\title{
STUDY ON NOISE POLLUTION AT CONSTRUCTION SITE
}

\author{
Geetha.M ${ }^{1}$, Ambika.D ${ }^{2}$ \\ ${ }^{I} P G$ scholar, Civil Engineering Department, Kongu Engineering College, Tamilnadu, India \\ ${ }^{2}$ Assistant Professor, Civil Engineering Department, Kongu Engineering College, Tamilnadu, India
}

\begin{abstract}
Construction sites grinds out deep noises, mostly from vehicles, equipment and array of machineries. Surplus noise is not only infuriating and diversionary, but can lead to hard of hearing, blood pressure, sleeping trouble and awful stress. High noise levels in construction escalate the nature and environment. Among various pollutions noise pollution from construction industry is one of the important contributions for the environment. The objective of this paper is to study some general information about the noise generated by the activities of construction. This imprecise consciousness data includes review of all noise level and their effects due to construction. The general study contains the circumstances which affects due to noise pollutants of construction sites in various places, methods and the results used in the reviews.
\end{abstract}

Keywords: Noise, Annoyance, Equipment, Exposure, Experiments

\section{INTRODUCTION}

The crucial contribution of noise from construction sites are mainly from the vehicles, equipments, breakers etc. Construction operations are arranged by different equipment contrast in noise levels. The noise level data of a construction site consideration depends on ambient scale levels. Each construction noise computation is carry out by the forecasting noise levels established for the particular site.

This general study consists of various studies which are, Noise emissions on construction sites and the impacts, modelling of construction noise for environmental impacts, noise annoyance due to construction worksites, construction noise exposure, and noise exposure of workers of the construction sector. From the above review materials the overall general study has been followed.

1) Noise emission evolution on construction sites. Measurement for controlling and assessing its impact on the people and on the environment: [Building and Environment 45 (2010) 711-717] explains about the noise which turn out through the construction activities is one of the main acoustic polluting essence for society. However, there is no particular standard for this activity, which validates its own effluent factors that make it phenomenon different from other operations. This experimental information's on construction sites have been measured through four averaging and integrating sound level meters with spectrum analyser included and a sound calibrator. The factors of sound emission for experimental data has been differentiate as five stages (excavation stage, frameworks, installation stage, roof stage, stage of walls) each stage have been analysed and compared with the standard level. The comparison among the values is to characterise the noise emission of the construction process. These stages of the construction process cannot be reasonably enviable regarding the spectra, except for the excavation stage, given that the only staggering thing is effect of the peak at low frequency. The results show that the measures for controlling the noise and the analysis of the acoustic impact which such activity produce in the concern specified area.

2) Modeling of Construction Noise for Environmental Impact Assessment: [Journal of Construction in Developing Countries, Vol.13. No.1, 2008] study deliberates that the noise levels generated at different construction equipments used in construction site and reviewed the procedure to forecast such noise in order to consider the environmental impact of noise. The method used for measuring is artificial neural networks (ANNs) for the prediction of noise. A back-propagation neural network (BPNN) model was compared with a general regression neural network (GRNN) model. The results showed that the ANN model showed to be an efficient technique for noise predictions required in the assessment of environmental impact of construction activities. The GRNN model was improved to the BPNN model in its ability of predicting construction noise.

3) Noise Annoyance Due to Construction Worksites [JRHS 2013; 13(2):201-207] Describes about the noise pollution which assist harmful health effects for humans. Noise outrage and interrelated problems, brings on noise effluents during the progress of building construction, have become increasingly significant. The study presents to assess the noise annoyance due to noise from construction worksites. The method used for ambient noise level of construction sites were measured through calibrated sound level meter. The results represent that significant relationship between noise annoyance and some factors including residing which floors had highest annoyance and ambient noise.

4) Noise exposure of workers of the construction sector [AIHA Journal 63:768-789(2002)] explains about physical contaminants due to noise in the construction sector. The 
negative effects caused by noise exposure due to construction will produce professional deafness or even permanent deafness. These effects influence the society; hence this study is to assess the noise exposure and to develop mechanisms for studying and proposing preventive solutions. This work has studied about the noise levels which the workers of the construction sector are apparent. The method used in this study to represents the measurements, have been derived by using a sound level meter and a dosimeter to collect data from workers devoted to different tasks in the construction process. The analysis of these noise levels is done through dosimeter and those values are compared with current regulations. The result shows that insufficient knowledge of the workers and agencies concerning high noise and their problems create harmful effects.

5) Assessing noise emission levels from earthwork construction equipment [Malaysian Journal of Civil Engineering 24(1):13-28 (2012)] Characterize about the noise emission levels from construction equipment, especially from earthwork equipments and their factors which affects the labours and the workers. This study explains and to investigate the emission level of noise of typical earthwork equipment, by the noise identified through the earthwork equipment is compared with British standard (BS5228:2009) values. The results shows that the comparison of measured data with British standard mentioned that at the planning stage of a project gives more assurance to the environmental impact assessment (EIA) practitioner in certifying particular measures to eliminate or reduce the adverse impacts of development projects.

\section{METHODOLOGY}

The study based upon the review papers which vouch for the noise pollution on construction sites and the exposure from the sites. The modality frames the mode of techniques used on the review papers. The calibrated sound level meter used for measuring dense equipment and machineries on construction sites. The noise emission levels of excavator and compactors mean sound pressure level has been done by noise level meter. The study also reasoned the mean emission value and standard deviation from the noise level meter.

The information of each equipment has done by various software's for isolated activities (extracting, processing and measuring parameters) especially software linked to the sound level meters has been used for unique process.

Noise explorer, Excel and Matlab has been done for processing and plotting the area. SPSS has been used for statistical analysis.

\section{CONCLUSION}

The overall concept of this paper is to study about noise level which takes place on construction sites. The noise from construction site at each journal shows distinct levels to represent the impacts of noise pollution due to construction.
The calibrated sound level meters and the dosimeters were mostly used to measure the noise levels during construction. The results obtained during construction were compared with British standards. The outcome of the noise level is to emphasis the harmful effects for the labours and to assess the problems due to noise pollution on construction. From this general study the impacts and the determination methods for noise level due to construction were assimilated.

\section{REFERENCES}

[1]. Boussabine A.H. (1997). Artificial neural networks for predicting noise from construction sites. Bldg. Acoustics. 4(3): 211-221.

[2]. Golmohammadi R. Noise and Vibration Engineering. 4th ed. Hamadan-Iran: Daneshjoo; 2010.

[3]. Irmer.V and Fischer-Sheikh Ali.E (1999); 'Reduction of noise emission of construction machines' due to the Blue Angel Award. Noise/News Int. 7:159-167

[4]. Jafferson.K and Vasudevan.R.N (1997) 'The prediction of construction site noise' - an example of the application of the old and new BS5228 methods. In: Proceedings of the Institute of Acoustics, 1997, vol. 19, part 8. pp. 245-250

[5]. LaBenz, P., A. Cohen, and B. Pearson: A noise and hearing survey of earth-moving equipment operators. Am. Ind. Hyg. Assoc. J. 28:117-128 (1967).

[6]. Malaysian Journal of Civil Engineering 24(1):13-28 (2012).

[7]. M.J. Ballesteros Building and Environment 45 (2010) 711-717.

[8]. Paulsen R. (2006) 'Noise exposure of construction workers'. Tampere (Finland).

[9]. Suggs C.W. (1981) 'Noise Problems of Hand and Power Tools', Noise-con 81, 339-342.

[10]. Suter A.(2002) Construction noise: exposure effects and the potential for remediation: a review and analysis. Am Ind Hygiene Assoc J; 63:768-89.

[11]. Harris R.A. and Bowlby. W (1987) Method for analyzing construction haul noise impacts. Journal of Construction Engineering and Management; 113(1):6-16.

\section{BIOGRAPHY}

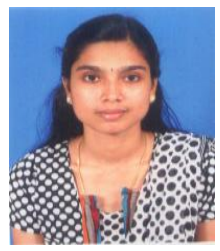

M.Geetha, PG scholar (M.E Construction Engineering and Management), Kongu Engineering College, Erode 